2019-08-01

\title{
Lived experiences of return to paid work following a brain injury
}

\author{
Beaulieu, Karen
}

http://hdl.handle.net/10026.1/14656

10.1177/0308022619860980

British Journal of Occupational Therapy

SAGE Publications

All content in PEARL is protected by copyright law. Author manuscripts are made available in accordance with publisher policies. Please cite only the published version using the details provided on the item record or document. In the absence of an open licence (e.g. Creative Commons), permissions for further reuse of content should be sought from the publisher or author. 
Title

Lived experiences of return to paid work following a brain injury

\title{
Short title
}

Return to paid work following a brain injury

\author{
Author list \\ Devon, UK

\section{Corresponding author} \\ Dr Karen Beaulieu \\ Associate Head of School Internationalisation \\ Faculty of Health and Human Sciences \\ University of Plymouth \\ Derriford Rd \\ Devon \\ PL68BH \\ UK \\ Karen.beaulieu@plymouth.ac.uk
}

Karen Beaulieu, Faculty of Health and Human Sciences, University of Plymouth,

\begin{abstract}
Introduction

Due to resulting psychosocial, cognitive, psychological, communication and/or physical difficulties following a brain injury, it is often difficult to return to paid work. Being in paid work is generally good for individuals' health, however currently only one third of the brain injury population manage to achieve this return.
\end{abstract}

\section{Method}

A descriptive phenomenological approach was used to collect and analyse data from ten male and six female individuals who had sustained either a moderate or severe traumatic or acquired brain injury. Unstructured interviews explored their experiences of return to paid work. Data analysis resulted in synthesised descriptions of their return to paid work lived experiences following a brain injury.

\section{Findings}

Sixty-one meaning units were established from the data, and six themes emerged: Coping with ongoing difficulties, Expectation and timing of return to work, Workplace colleague reactions, Things that help, Change and return to work options, and Feelings of success.

\section{Conclusion}

Findings can be used to develop a more consistent approach to return to paid work, will inform future Occupational Therapy practice and return to paid work rehabilitation. Occupational Therapists need to support these individuals to cope 
with the ongoing difficulties facing them, especially in relation to fatigue, memory and transportation difficulties.

\section{Keywords}

Brain injury

Return to work 


\section{Introduction}

It is generally accepted that being in paid work is good for an individual's health however; it has been highlighted that less than half of individuals return to work one to ten years following a traumatic brain injury (Ponsford et al., 2014). Furthermore, it has also been established that only $40 \%$ of individuals with an acquired brain injury, who worked prior to their injury, return to work within two years post injury (Van Velzen et al., 2009).

Friedland and Potts (2014) reported a $40 \%$ return to paid work rate in the UK, and it would appear that this low return to paid work rate following a brain injury is not solely isolated to the UK, but is of international concern (Shigaki et al., 2009). Despite similar low international return to work rates however, the recovery journey of individuals following these injuries appears to vary in different countries in relation to how long it takes to return to paid work and the rehabilitation provided. It is currently unclear how rehabilitation following a brain injury impacts return to paid work rates, and this is made more difficult to understand as Occupational Therapists rarely describe their interventions (Phillips et al., 2010).

\section{Research rationale}

It is difficult following a brain injury to return to paid work due to the resulting psychosocial, cognitive, psychological, communication and/or physical difficulties, which often have a negative effect on an individual's ability to seek or maintain employment (Schonbrun et al., 2007; Donker-Cools et al., 2018). Saltychev et al. (2013) suggest that returning to work and maintaining employment following a life-changing event, such as a traumatic brain injury, can be challenging due to the complex interaction of the potential resulting physical, cognitive and emotional impairments. It is therefore important to have a deeper understanding of the return to paid work experiences of individuals following a brain injury, and to explore what these individuals say about their experiences of barriers and success factors relating to return to work. This improved understanding could lead to improvements in future rehabilitation and improved quality of life for these individuals.

\section{Background literature review}

Five key themes summarise existing and relevant knowledge.

1. Fatigue.

2. Cognitive difficulties, anxiety and depression.

3. Self-awareness, efficacy and identity.

4. Invisibility and stigma.

5. External factors. 
Fatigue

On exploring return to work in the UK with 10 participants following traumatic brain injuries, Hooson et al. (2013) identified that excessive fatigue generated a fear of failure for these individuals. This is supported by the findings of Velzen et al. (2011) in the Netherlands. Velzen et al. (2011) established tiredness as the most reported limiting factor related to return to work following research with 12 adults who had experienced moderate to severe acquired brain injuries. Also in the Netherlands, Donker-Cools et al. (2018) highlighted work related fatigue as problematic in research with 10 individuals following traumatic brain injuries and seven employers. In addition to this, Rubenson et al. (2007) in Sweden, on exploring experiences of return to work with eight participants following acquired brain injuries, also reported fatigue to be a barrier. Further research related to post injury fatigue is therefore required.

Cognitive difficulties, anxiety and depression

In Sweden, Bjorkdahl (2010) explored return to work with 65 individuals following traumatic brain injuries. Most frequent problems reported were remembering (96\%) and concentrating (91\%). Similarly, in the USA, Artman and McMahon (2013) researched the self-reported functional limitations of 160 individuals following traumatic brain injury in relation to job maintenance following return to work, and found memory loss, attention, concentration and behavioural difficulties most reported. Despite Artman and McMahon (2013) relying on the self-report of participants who may have lacked self-awareness, their findings were consistent with Benedictus et al. (2010) in the Netherlands. Benedictus et al. (2010) on evaluating cognitive and behavioural disturbances related to return to work for 434 individuals following traumatic brain injury found that participants encountered problems with cognitive (62\%), behavioural (55\%) and social difficulties (49\%). Furthermore, in Finland, Saltychev et al. (2013) on evaluating evidence on pre and post injury predictors of vocational outcome identified that level of depression and anxiety may be predictive for vocational outcome following traumatic brain injury. Additional evidence provides limited predictions for return to paid work relating to the presence of depression, mental illness or behavioural disabilities (Grauwmeijer et al., 2012; Van der Horn et al., 2013; Waljas et al., 2014). This suggests that cognitive difficulties, anxiety and depression may affect return to paid work, but the severity and potency of these symptoms remain unclear.

Self-awareness, efficacy and identity

The level of self-awareness following a brain injury can affect return to paid work, although evidence supporting this is limited (Ownsworth et al., 2010). Findings suggest that individuals following a brain injury may use return to work as a vehicle to re-establish their self-efficacy and identity, but this requires further research (Soeker et al., 2012; Hooson et al., 2013). It is plausible that individuals may use work to re-establish their identity and to adapt self-efficacy, but this requires deeper investigation.

Invisibility and stigma

Gilworth et al. (2008) explored the work related experiences in the UK of 33 workers who had sustained mild to moderate brain injuries, and established that 
these participants had difficulties due to the invisibility of their disability. In South Africa, ten participants following mild to moderate traumatic brain injury also highlighted stigma as the cause of their loss of jobs, and that stigma was negative when obtaining new jobs (Soeker, 2011: 2012). Invisibility and stigma may be linked to sustaining work following a brain injury, but both require deeper investigation.

\section{External factors}

Factors such as employer and colleague support and poor guidance have been identified as potentially influencing return to paid work following a brain injury. In France, from data collected from 100 individuals following traumatic brain injuries, Bonneterre et al. (2013) concluded that these individuals would have been further helped with more assistance within their workplace. Bonneterre et al. (2013) concluded that workplace support was key for job retention over a medium term of four to eight years. Van Velzen et al. (2011) also acknowledged the importance of employer and colleague support; in particular, that employers and colleagues are informed about acquired brain injury. Furthermore, in Canada, following a comparison of current practices to best practices with 13 vocational professionals, Stergiou-Kita et al. (2016) highlighted a need for vocational evaluators to engage better with employers. In the Netherlands, Donker-Cools et al. (2018) have identified poor guidance as a factor following research with 10 individuals following traumatic brain injuries and seven unrelated employers. Interestingly the injured individuals reported poor guidance and support and the need for understanding and acceptance of the limitations resulting from brain injury as barriers to return to work, whereas the employers did not.

It is currently difficult and challenging to predict vocational outcome, but this review highlights the need to improve current understanding of the factors affecting return to paid work following a brain injury (Saltychev et al., 2013).

\section{Research aim}

To explore what individuals say about their experiences of the barriers and success factors relating to return to paid work following a brain injury.

\section{Research objectives}

1. To collect and analyse data about the return to paid work lived experiences of individuals following an acquired or traumatic brain injury to establish potential barriers and success factors.

2. To use research findings to inform future Occupational Therapy practice and return to paid work rehabilitation.

\section{Method}

Phenomenology, both a philosophy and a qualitative approach, gets to the essence of a phenomenon, and was used in this research as it allowed the unique meaning of work to be explored from each individual's lived experience. This descriptive phenomenological research approach, developed by Giorgi (2000a), was used to systematically collect and analyse data as, whilst remaining faithful to the original Husserlian approach, it provided truly descriptive lived experience data (Husserl, 2001). 
Research ethics

Via the Integrated Research Application System, this research received ethical approval from the National Health Service Research Ethics Committee, reference number 10/H0403/95, 2010.

\section{Participant recruitment}

Participants were included if they were over the age of 18 and able to consent. They needed sufficient communication skills to participate in an interview, and to have sustained either a traumatic or acquired brain injury (tumour removal, subarachnoid haemorrhage, burst aneurysm) of moderate to severe severity (Glasgow Coma Scale score of 12 or below). Participants needed to have returned to full or part time paid work within England for a minimum of six months post injury.

Participants were excluded if unable to make their own decisions, or to understand or speak English with a degree of fluency. Individuals, who had sustained a congenital brain injury, had degenerative brain disease, had sustained an ischaemic stroke or were in unpaid work were excluded, in addition to those that had sustained a mild brain injury (Glasgow Coma Scale score of 13-15) or diagnosed with a psychiatric disorder.

Snowball sampling was used with hard copy and digital posters being provided to Headway UK, a brain injury association and charity set up to help and support people affected by brain injury, and National Health Service and Private Brain Injury Rehabilitation Services within England. Potential participants contacted the researcher after seeing posters predominantly via Headway UK. Following return of signed consent and satisfying the inclusion criteria 16 participants were recruited.

\section{Data collection}

Data were collected from 10 male and six female individuals who had sustained brain injuries. Eleven participants had an acquired brain injury and five a traumatic brain injury. Participant's median age at the time of their injury was 37 years of age and their median age at interview was 47 years. Fifteen of the participants had received initial varied times in acute rehabilitation and one participant received no rehabilitation. Only two participants had received limited Vocational Rehabilitation, described as brief periods in an Occupational Therapy Department. Participants represented a wide range of paid jobs and settings, which included a Global Banker, Weed Sprayer, Engineer, and Classroom Assistant. Table one presents the Participant pseudonyms and more detailed information.

Participants were interviewed in person consecutively, and at a suitable date and location to them. Participants lived experiences were explored and they were viewed as experts. Unstructured and recorded interviews were carried out. This involved the researcher asking one open-ended trigger question at the start, and continued until participants finished their descriptions. This trigger question asked participants to describe their experience of return to paid work, highlighting any barriers and success factors that they had experienced. 
Researcher preconceptions were bracketed by using a reflective diary and reflexivity applied by the researcher critically analysing influences on their practice and the potential consequences on their analysis and outcome. This was essential to analyse how knowledge was generated, and for the researcher to analyse underlying assumptions and influences.

Data analysis

Giorgi's four descriptive phenomenological essential steps to data analysis were used (Giorgi, 2000a). Firstly, the participant's recorded transcripts were read and reflected upon to gain a sense of the overall description. Secondly, the researcher returned to each participant's original description a second time with the intention of discriminating meaning units with a focus on the research aim. Thirdly, the researcher went through all of the emerging meaning units and explored the psychological insight contained within them. Fourth and lastly, the researcher then synthesised all the transformed meaning units into a general situated description of the overall phenomenon that illustrated each emergent theme and synthesised all participant descriptions of their lived experiences of return to paid work following their brain injury.

\section{Trustworthiness and verification}

Trustworthiness is promoted with raw data being available for scrutiny. Replicability would be possible by having another researcher re-perform the analyses already done or by other researchers in other places obtaining new descriptions of this same phenomenon whilst applying the same method, enabling them, in principle to come up with the same findings (Giorgi, 2000b). Verification was enhanced with another phenomenological researcher checking $50 \%$ of the data analysis. This Giorgi method was sensitive to the research aim, collected differing descriptive data, and provided a truly descriptive lived experience.

\section{Findings}

From the 61 meaning units established from participant raw data six themes emerged. Table two presents more detailed information of how the following six themes emerged from the meaning units:

1. Coping with ongoing difficulties.

2. Expectation and timing of return to work.

3. Workplace colleague reactions.

4. Things that help.

5. Change and return to work options.

6. Feelings of success.

Presentation of the six themes includes all participant descriptions and selected quotations.

\section{Coping with ongoing difficulties}

Difficulties with self-awareness, cognition, fatigue, Welfare benefits and transport were experienced. Participants described increasing awareness that their difficulties related to their injury. Martin expressed: -

"When I got back to work, I was on the same train but on a different track. I felt self-aware and that I stuck out like a sore thumb". 
Memory difficulties, the most prevalent, presented as difficulty talking to people when unable to remember, and getting into trouble for asking too many questions.

Most participants experienced constant exhaustion. Phil described: -

"Everything I tried made feeling exhausted harder, I was failing, and nobody had told me".

Fatigue resulted in time off and job loss. Defined by Martin: -

"I'd get angry when tired or when plans changed. It was real fatigue, extreme tiredness".

Half of the participants experienced Welfare benefit difficulties. Phil described: -

"When you get (earn) more on benefits than you get working, it feels like you are in a continuous circle that you can't break out of".

Most were unable to drive post injury relying on alternative transportation. Coping with crowds made this worse, resulting in busy bus and train avoidance. Melvin explained: -

"I felt I deserved more sympathy when commuting with thousands of people, not one gave two hoots about me".

\section{Expectation and timing of return to work}

Participants expected and were driven to get back to who they were before their injury. Melvin expressed: -

"My primary goal was to get back to what I did before, the sense of familiar was comforting cause so much had changed, I craved something that had stayed the same".

They expected the fastest possible return to work and pre-injury lifestyle. Slow phased return (between one and three-years post injury) was experienced by most, and was more successful and satisfying. A fast return (between two and eight-weeks post injury), for less than half of the participants, resulted in failure. Eleven participants returned slowly (from a four-hour working day every two weeks to working three short days each week). Fast return was a direct barrier (two weeks post injury) resulting in failure. Chris explained: -

"I was on full time duties after four weeks. Everything just went wrong, after that I was demoted and kicked out".

\section{Workplace colleague reactions}

Six participants experienced negative colleague reactions regarding a lack of understanding about their brain injury. Dawn expressed: -

"Some would look at me and say I can't see anything wrong with you".

Three participants described more understanding colleagues. Sandra explained: -

"My colleagues were aware of what had happened to me and were very supportive".

Three experienced social exclusion. Dawn described: - 
"I sat facing a wall and they were all behind me in the office. They arranged socials, never invited me, and talked about it in front of me".

\section{Things that help}

Half of the participants described helpful professionals including Social Work, Occupational Therapy, Headway UK, Occupational Health and Personnel Managers. Additionally, Sandra explained: -

"My manager and colleagues were aware of what had happened to me, and were supportive. Where it hasn't worked out people didn't know my history, the biggest help was people who understood".

Further helpful experiences described by the participants included practical support received from professionals and services, and emotional support from families, friends, colleagues and line managers. Phil described: -

"My Occupational Therapist did a lot to help and support me, she came into work a few times to see me, and she talked to the Managing Director a few times to see how I was getting on".

The participants explained how important they felt it was to have supportive colleagues working with and around them. Chris expressed: -

"My boss is an understanding bloke, and em he just lets anyone get on with the job. He put me with a lovely colleague who I team up with nicely. The people are definitely important".

\section{Change and return to work options}

Six participants described difficulties where workplaces and colleagues had changed in their absence. Melvin described: -

"The big problem for me was a lot of the people had changed as it was over a year on..., and quite a few that I had worked with had changed, (and) moved on. New people had come in, so going back I genuinely felt like the new boy again...., it would be more stressful going into a job where $I$ had to learn from scratch, to a team and people I didn't know..., in a different job or department I think I would have crumbled".

Two of the participants described becoming aware of changes to their previous working practice. Peter explained: -

"Unfortunately I was letting people down you know, and I'd never done that in my entire working life, so you know I was making promises that I just couldn't keep".

No established return to paid work route or pathway existed for participants, and they returned via different routes and paths. Only seven participants (Melvin, Peter, Julian, Martin, Dawn, Verna and John) returned to similar or related preinjury jobs, with most participants changing jobs. Different routes and paths included Chris using a Council Retraining Scheme, Gill having private work retraining, and Edward and Dave doing Work Placements. Fiona returned via the Shaw Trust, a Charity that helps young people and adults across the UK and internationally to enter work, and Phil through voluntary work. Participants Sarah, Carl and Sandra found jobs on the open market. 


\section{Feelings of success}

Success was associated with return to work, and to the person and life participants identified with before injury. Melvin explained: -

"I was looking at the job as a big part of who I was, but I wanted recognition em success of having that job in the city, and that level of seniority was important to me getting back to doing a large degree of what I did before".

Success boosted self-esteem as expressed by Carl: -

"The biggest satisfaction is to go and see a door hanging off its hinges, and then fix it. Being back in work has helped my self-esteem".

Melvin, Edward, Verna, Fiona and Sandra all described feeling good and valued by earning their own way again and feeling successful being back at work. Verna summarised her experience:-

"I like having a job so yeh that's what I enjoy and feel successful about being back at work. Working feels good, and to earn my own way".

Fiona explained further:-

"I feel valued, as they could have easily retired me on medical grounds"

\section{Discussion and implications}

Following exploration of the return to paid work lived experiences of 16 brain injured participants barriers and success factors were highlighted for discussion.

The participant findings corroborate previously established poor return to work rates and provide description of factors that may contribute to this (Friedland and Potts, 2014). A barrier highlighted was that no established return to paid work route or pathway existed, and the majority of participants had to find themselves jobs on the open market despite the differing and diverse routes and paths that they took. Just under half of the participants experienced job restructuring following return to work, which created further barriers. Implications are that a more consistent return to paid work approach could inform future Occupational Therapy practice and rehabilitation.

Participants expected to return to work immediately, and described being driven to achieve this in order to return to their pre-injury life. They also described that a fast return to work resulted in failure, and that slow return to work was more successful. More detailed advice and support needs to be provided about the consequences of a fast and immediate return to work, and slower and more supported return to work facilitated. Occupational Therapists need to support and guide individuals better to return to paid work at the best time.

Consistent with Bjorkdahl (2010) and Hooson et al. (2013), the most prevalent on-going difficulties experienced by the majority of the participants were fatigue and having a poor memory, and for half of the participants' transportation and Welfare benefit difficulties. Implications are that Occupational Therapists need to assess and help individuals to manage fatigue and memory difficulties from the earliest opportunity, and to continue supporting them to manage these during return to work. In addition, different forms of transportation need to be arranged 
that do not increase fatigue levels, and further assistance provided to access ongoing Welfare benefit support.

Ownsworth et al. (2010) suggest that following a brain injury, individuals with a reduced or an impaired level of insight have difficulty returning to work. Only five of the participants linked feelings of success to their improving insight and self-awareness, and described their recovered ability to perceive personal changes in themselves. These experiences reinforce the importance of insight and self-awareness, and the importance of brain-injured individuals being able to understand their abilities to help them to succeed. Occupational Therapists need to be mindful that individuals following a brain injury may use return to work as a vehicle to help them to try to re-establish their self-awareness, but also that feelings of success may be linked to improving insight and selfawareness.

The invisibility of some disabilities such as fatigue and memory difficulties have been highlighted as a potential barrier to return to work (Gilworth et al., 2008). Participant descriptions confirm that colleague awareness, knowledge and understanding of brain injury is important and influences and impacts the way colleagues react, and are able to offer support within the workplace. Implications for Occupational Therapy are that for return to paid work to be successful workplace colleague awareness of invisible difficulties such as fatigue and memory difficulties need to be better understood for work colleagues to be able to react appropriately and supportively.

\section{Contribution}

Findings inform the return to paid work guidance for Occupational Therapists when working with brain-injured individuals. Specifically, in relation to advocating a slow and supported return to work, the need to assess and support individuals to manage fatigue and memory difficulties from the earliest opportunity, and to establish forms of transportation that do not increase fatigue. In addition, further support is needed to help these individuals to access ongoing Welfare benefit support as well as helping workplace colleagues increase their awareness of invisible problems such as fatigue and memory difficulties and to better understand them.

\section{Limitations}

Despite rich descriptive phenomenological data being collected, the findings only describe the experiences of 16 brain-injured participants from within central and southern England. The use of interviews relied on participants recall from previous years and such a retrospective view may have limited the range and depth of their descriptions. Findings may have differed if collected from a different group and included different injury related variables. In addition, the majority of participants had been unable to access Vocational Rehabilitation and had experienced varying return to paid work timescales. To triangulate findings however, there is a need for further research within, and beyond the UK to look at this phenomenon under different contexts to explore similarities that may have wider generalizability.

\section{Conclusion}


Following exploration of the return to paid work lived experiences of individuals following an acquired or traumatic brain injury, barriers and success factors have been established, and the findings can be directly used to inform future Occupational Therapy practice and return to paid work rehabilitation.

Occupational Therapists need to focus and support these individuals to cope with the ongoing difficulties facing them, especially in relation to fatigue, memory and transportation difficulties. Expectations regarding the timing of their return to work needs to be addressed and a slow return advocated and supported to increase potential success. Workplace colleagues need to be better advised to promote their understanding of brain injury and ongoing difficulties in order to promote more positive reactions and ongoing support in the workplace.

Occupational Therapists need to consider that individuals following a brain injury may use return to work to help them to re-establish their self-awareness, and to therefore support them to become more self-aware and to experience feelings of success.

\section{Key findings}

Occupational Therapists need to support individuals following a brain injury to cope with ongoing fatigue, memory and transportation difficulties, and in relation to the timing of their return to work.

\section{What the study has added}

Fatigue, memory and transportation difficulties need to be assessed and supported from the earliest opportunity, a slow return to paid work advocated, and workplace colleagues helped to understand invisible difficulties. 


\section{Research ethics}

Ethical approval was obtained from the National Health Service Research Ethics Committee, reference number 10/H0403/95, 2010.

\section{Consent}

All participants provided written informed consent to be interviewed for the study.

\section{Declaration of Conflicting Interests}

The author declared no potential conflicts of interest with respect to the research, authorship, and/or publication of this article.

\section{Funding}

The author disclosed receipt of the Irwin Mitchell Research Award in 2011 to part support PhD study from Irwin Mitchell Solicitors and the UK Occupational Therapy Research Foundation, Royal College of Occupational Therapists.

\section{Acknowledgements}

Irwin Mitchell Solicitors, the UK Occupational Therapy Research Foundation, and the PhD supervisory team: Emeritus Professor Annie Turner, Professor Jacqueline Parkes, and Professor Jackie Campbell. 


\section{References}

Artman L and McMahon B (2013) Functional limitations in traumatic brain injury and their relationship to job maintenance following work re-entry. Journal of Vocational Rehabilitation 39: 13-21.

Benedictus M, Spikman J, Van der Naalt J (2010) Cognitive and behavioral impairment in traumatic brain injury related to outcome and return to work. Archives of Physical Medicine and Rehabilitation. 91: 1436-1441.

Björkdahl A (2010) The return to work after a neuropsychological programme and prognostic factors for success. Brain Injury. 24(9): 1061-1069.

Bonneterre V, Perennou D, Trovatello V, Mignot N, Segal P, Balducci F, Laloua F, De Gaudemaris R (2013) Interest of workplace support for returning to work after a traumatic brain injury: A retrospective study. Annals of Physical and Rehabilitation Medicine. 56: 652-662.

Donker-Cools B, Schouten M, Wind H, Frings-Dresen, M (2018). Return to work following acquired brain injury: the views of patients and employers. Disability and Rehabilitation. 40(2): 185-191.

Friedland D and Potts J (2014) Return to work following moderate-severe traumatic brain injury: A UK community sample. Clinical Psychology Forum. 259: 16-19.

Gilworth G, Eyres S, Carey A, Bhakta B, Tennant A (2008) Working with a brain injury: personal experiences of returning to work following a mild or moderate brain injury. Journal of Rehabilitation Medicine. 40: 334-339.

Giorgi A (2000a) Concerning the Application of Phenomenology to Caring Research. Scandinavian Journal of Caring Science. 14: 11-15.

Giorgi, A. (2000b) The status of Husserlian phenomenology in caring research. Scandinavian Journal of Caring Sciences. 14(1), pp.3-10.

Grauwmeijer E, Heijenbrok-Kak M, Haitsma I, Ribbers G (2012) A prospective study on employment outcome 3 years after moderate to severe traumatic brain injury. Archives of Physical Medicine and Rehabilitation. 39(June): 993-999.

Hooson J, Coetzer R, Stew G, Moore A (2013) Patients' experience of return to work rehabilitation following traumatic brain injury: A phenomenological study. Neuropsychological Rehabilitation. 23(1): 19-44.

Husserl E (2001) The shorter logical investigations. 1st abridged ed. London: Routledge. 
Ownsworth T (2010) A metacognitive contextual approach for facilitating return to work following acquired brain injury: Three descriptive case studies. Work. 36: 381-388.

Phillips J, Drummond A, Radford K, Tyerman A (2010) Return to work after traumatic brain injury: recording, measuring and describing occupational therapy intervention. British Journal of Occupational Therapy. 73(9): 422-430.

Ponsford J L, Downing M G, Olver J, Ponsford M, Archer R, Carty M, Spitz G (2014) Longitudinal follow-up of patients with traumatic brain injury: Outcome at two, five, and ten years post-injury. Journal of Neurotrauma. 31(1): 64-77.

Rubenson C, Svensson E, Linddahl I, Bjorklund A (2007) Experiences of returning to work after acquired brain injury. Scandinavian Journal of Occupational Therapy. 14: 205-214.

Saltychev M, Eskola M, Tenovuo O, Laimi, K (2013). Return to work after traumatic brain injury: Systematic review. Brain Injury. 27(13-14): 1516-1527.

Schonbrun S, Sales A, Kampfe C (2007) RSA services and employment outcome in consumers with traumatic brain injury. Journal of Rehabilitation. 73(2): 2631.

Shigaki C, Johnstone B, Schopp L (2009) Financial and vocational outcomes 2 years after traumatic brain injury. Disability and Rehabilitation. 31(6): 484-489.

Soeker M (2011) Occupational adaptation: A return to work perspective of persons with mild to moderate brain injury in South Africa. Journal of Occupational Science. 18(1): 81-91.

Soeker M, Van Rensburg V, Travill A (2012) Individuals with traumatic brain injuries perceptions and experiences of returning to work in South Africa. Work. 42: $589-600$.

Stergiou-Kita M, Grigorovich A, Dawson D, Bottari C, Hebert D (2016) Do current vocational evaluation practices in traumatic brain injury align with best practices? Strengths, challenges and recommendations. British Journal of Occupational Therapy. 79(5): 309-322.

Van der Horn H, Spikman J, Jacobs B, Van der Naalt J (2013) Postconcussive complaints, anxiety, and depression related to vocational outcome in minor to severe traumatic brain injury. Archives of Physical Medicine and Rehabilitation. 94: 867-874.

Van Velzen J, Van Bennekom C, Edelaar M, Sluiter J, Frings-Dresen M (2009) How many people return to work after acquired brain injury? A systematic review. Brain Injury. 23(6): 473-488.

Van Velzen J, Van Bennekom C, Van Dormolen M, Sluiter J, Frings-Dresen M (2011) Factors influencing return to work experienced by people with acquired brain injury: a qualitative research study. Disability and Rehabilitation. 33(2324): 2237-2246. 
Waljas $M$, Iverson $G$, Lange $R$, Liimatainen $S$, Hartikainen $K$, Dastidar $P$, Soimakallio S, Ohman J (2014) Return to work following mild traumatic brain injury. Journal of Head Trauma Rehabilitation. 29(5): 443-450 
Table one: The Participant pseudonyms and additional information.

\begin{tabular}{|c|c|c|c|c|c|c|c|c|}
\hline $\begin{array}{l}\text { Participant } \\
\text { number }\end{array}$ & Pseudonym & Sex & $\begin{array}{c}\text { Type of } \\
\text { brain injury }\end{array}$ & $\begin{array}{c}\text { Time in } \\
\text { acute } \\
\text { rehabilitation }\end{array}$ & $\begin{array}{c}\text { Received } \\
\text { Vocational } \\
\text { Rehabilitation }\end{array}$ & $\begin{array}{c}\text { Length of } \\
\text { time since } \\
\text { injury }\end{array}$ & $\begin{array}{l}\text { Job at time of } \\
\text { injury } \\
\text { *All worked full } \\
\text { time }\end{array}$ & $\begin{array}{l}\text { Job at time of interview } \\
\text { *All work part time }\end{array}$ \\
\hline 1 & Melvin & Male & $\begin{array}{l}\text { Acquired } \\
\text { brain injury } \\
\text { (ABI) }\end{array}$ & 12 months & No & 13 years & Sales Manager & Global Banker \\
\hline 2 & Phil & $M$ & $\begin{array}{l}\text { Traumatic } \\
\text { brain injury } \\
\text { (TBI) }\end{array}$ & 1 month & No & 21 years & Factory worker & Post Room Assistant \\
\hline 3 & Peter & $M$ & ABI & 24 months & No & 5 years & $\begin{array}{l}\text { Self-employed } \\
\text { builder }\end{array}$ & Engineer \\
\hline 4 & Chris & $M$ & ABI & 1 week & No & 28 years & Armed Forces & School Cleaner \\
\hline 5 & Julian & $M$ & $\mathrm{ABI}$ & 6 months & No & 10 years & Admin assistant & Weed Sprayer \\
\hline 6 & Sarah & Female & ABI & 3 months & No & 7 years & $\begin{array}{l}\text { Personal } \\
\text { Assistant }\end{array}$ & Recently Unemployed \\
\hline 7 & Martin & $M$ & TBI & 3 months & $\begin{array}{l}\text { Briefly in OT } \\
\text { Department }\end{array}$ & 31 years & $\begin{array}{l}\text { Apprentice } \\
\text { engineer }\end{array}$ & Handyman \\
\hline 8 & Dawn & $\mathrm{F}$ & ABI & 18 months & No & 9 years & $\begin{array}{l}\text { Accounts } \\
\text { administrator }\end{array}$ & Unemployed \\
\hline 9 & Edward & $M$ & TBI & 6 weeks & No & 16 years & $\begin{array}{l}\text { University } \\
\text { student }\end{array}$ & Support Worker \\
\hline 10 & Gill & $\mathrm{F}$ & $A B I$ & 1 month & No & 1 year & Sales manager & Unemployed \\
\hline 11 & Dave & $M$ & $A B I$ & 3 months & $\begin{array}{l}\text { Briefly in OT } \\
\text { Department }\end{array}$ & 12 years & Clerk & $\begin{array}{l}\text { Administrative } \\
\text { Assistant }\end{array}$ \\
\hline 12 & Carl & $M$ & ABI & 1 month & No & 2 years & $\begin{array}{l}\text { Self-employed } \\
\text { builder }\end{array}$ & School Caretaker \\
\hline 13 & Verna & $\mathrm{F}$ & TBI & 12 months & No & 6 years & Clerk & Classroom Assistant \\
\hline 14 & John & $M$ & $A B I$ & 3 months & No & 12 years & Train driver & Train Cleaner \\
\hline 15 & Fiona & $\mathrm{F}$ & TBI & None & No & 2 years & $\begin{array}{l}\text { Self-employed } \\
\text { sales }\end{array}$ & Territorial Army Instructor \\
\hline 16 & Sandra & $\mathrm{F}$ & ABI & 8 weeks & No & 13 years & Travel agent & Telesales Assistant \\
\hline
\end{tabular}


Table two: The 6 themes to emerge from the 61 meaning units:

\begin{tabular}{|c|c|}
\hline Emergent themes & Meaning units \\
\hline $\begin{array}{l}\text { Theme } 1 \\
\text { Coping with ongoing difficulties }\end{array}$ & $\begin{array}{l}16 \text { meaning units } \\
\text { 1. Ongoing residual cognitive issues } \\
\text { 2. Impact of fatigue } \\
\text { 3. Transport issues } \\
\text { 4. Barriers to self-worth } \\
\text { 5. Discrimination } \\
\text { 6. Frustrations } \\
\text { 7. Lack of information } \\
\text { 8. New learning } \\
\text { 9. Residual physical problems } \\
\text { 10. Residual mental health problems } \\
\text { 11. Residual social problems } \\
\text { 12. Abusing opportunity } \\
\text { 13. Early post injury needs } \\
\text { 14. Environment issues } \\
\text { 15. Set backs } \\
\text { 16. Benefit issues }\end{array}$ \\
\hline $\begin{array}{l}\text { Theme } 2 \\
\text { Expectation and timing of return to work }\end{array}$ & $\begin{array}{l}6 \text { meaning units } \\
\text { 1. Expectation to return to work } \\
\text { 2. Fast return to work } \\
\text { 3. Slow phased return } \\
\text { 4. Sick note period } \\
\text { 5. Working speed } \\
\text { 6. Reaction to slow phased return }\end{array}$ \\
\hline $\begin{array}{l}\text { Theme } 3 \\
\text { Workplace colleague reactions }\end{array}$ & $\begin{array}{l}5 \text { meaning units } \\
\text { 1. Colleague reactions at work } \\
\text { 2. Line manager issues } \\
\text { 3. Lack of sympathy } \\
\text { 4. Bullying } \\
\text { 5. Feeling unwanted }\end{array}$ \\
\hline $\begin{array}{l}\text { Theme } 4 \\
\text { Things that help }\end{array}$ & $\begin{array}{l}10 \text { meaning units } \\
\text { 1. Professionals who helped } \\
\text { 2. Helpful colleagues } \\
\text { 3. Helpful managers } \\
\text { 4. Access to work } \\
\text { 5. Family support } \\
\text { 6. Financial support } \\
\text { 7. Positive practical support } \\
\text { 8. Positive mental strategy } \\
\text { 9. Positive pre links with work } \\
\text { 10. Helpful environment }\end{array}$ \\
\hline $\begin{array}{l}\text { Theme } 5 \\
\text { Change and return to work options }\end{array}$ & $\begin{array}{l}19 \text { meaning units } \\
\text { 1. Job restructuring } \\
\text { 2. Alternatives options to return } \\
\text { to work } \\
\text { 3. Return to work factors } \\
\text { 4. Workplace had moved on } \\
\text { 5. Loss of job post return to work } \\
\text { 6. Job coaching } \\
\text { 7. Adapting to change } \\
\text { 8. Jobs found themselves } \\
\text { 9. Medical retirement } \\
\text { 10. Practical return to work issues }\end{array}$ \\
\hline
\end{tabular}




\begin{tabular}{|c|c|}
\hline & $\begin{array}{l}\text { 11. Reactions to alternatives to } \\
\text { return to work } \\
\text { 12. Work retraining } \\
\text { 13. Workstep } \\
\text { 14. Workbridge } \\
\text { 15. Work placements } \\
\text { 16. Mentor to others } \\
\text { 17. Work solutions } \\
\text { 18. Shaw trust } \\
19 . \text { Voluntary work }\end{array}$ \\
\hline $\begin{array}{l}\text { Theme } 6 \\
\text { Feelings of success }\end{array}$ & $\begin{array}{l}5 \text { meaning units } \\
\text { 1. Feeling of success/achievement } \\
\text { 2. Feeling whole again } \\
\text { 3. Insight/self-awareness } \\
\text { 4. Personal perceived change } \\
\text { 5. Returning to health and work }\end{array}$ \\
\hline
\end{tabular}

